\title{
The contribution of functional neurosurgery to the understanding of the physiopathology of Parkinson's disease
}

\author{
Juan Antonio Barcia ${ }^{1}$, Fernando Alonso-Frech ${ }^{2}$ \\ ${ }^{1}$ Neurosurgery Department Hospital Clínico San Carlos, Madrid, Spain \\ ${ }^{2}$ Movement Disorders Unit, Neurology Department Hospital Clínico San Carlos, Madrid, Spain; f.frech@yahoo.es
}

Received 30 November 2012; revised 14 January 2013; accepted 20 January 2013

Copyright (C) 2013 Juan Antonio Barcia, Fernando Alonso-Frech. This is an open access article distributed under the Creative Commons Attribution License, which permits unrestricted use, distribution, and reproduction in any medium, provided the original work is properly cited.

\begin{abstract}
Functional neurosurgery is nowadays a recognized treatment for advanced Parkinson's disease with pharmacologically uncontrolled symptoms. This procedure brings us the unique opportunity to deepen in the knowledge of PD's physiopathology by recording patients' neural activity, and possibly in the future it will let us select the appropriate target and the optimal chronic stimulation pattern.
\end{abstract}

Keywords: Parkinson's Disease; Functional Neurosurgery; Oscillatory Activity

\section{INTRODUCTION}

Parkinson's Disease (PD) is the second most frequent degenerative disorder after Alzheimer's Disease [1,2].

It is characterized by the degeneration of the pigmented dopaminergic neurons at the Substantia Nigra, pars compacta $(\mathrm{SNc})$ and at the Ventral Tegmental Area in the mesencephalon. This degeneration produces dopaminergic depletion at the striatum, with the loss of the modulation over the neuronal circuits of the striatum and the rest of the basal ganglia [3-5].

Levodopa intake produces a spectacular and sustained effect over the symptoms of highly disabled PD patients.

It was early noted that even if levodopa constitutes an efficacious treatment to alleviate most of the cardinal symptoms of PD, chronic levodopa treatment produces motor and psychiatric complications, sometimes more disabling than the proper disease [6,7].

The motor complications arising along the evolution of PD can be divided into two main categories: those related to the pharmacologic treatment of the disease (fluctuations and diskynesias), and those related to the extent and evolution of the degenerative disease, limited first to the dopaminergic system, but later generalized.

During the last decades, the scientific community has pursued the study of the physiopathologic mechanisms of these complications and the search for solutions [8-10] and even if it is true that the clinical management of PD has notably changed [11], today the pharmacological treatment of advance PD is still a problem to be resolved.

During the mid 80s, a physiopathological model of the basal ganglia (BG) was developed, based in anatomical and neurochemical studies, which considers that the BG belong to a distributive cortico-subcortical system organized anatomically and functionally in parallel loops. This model outlines the BG circuits in two pathways, the direct and the indirect ones, with opposing effects, connecting the striatum with the output nuclei [12].

The greatest success of this model has been its ability to predict a hyperactivity of the subthalamic nucleus (STN) and the output nuclei Globus Pallidus internus (GPi) and Substantia Nigra pars reticulata (SNr) in the PD state, leading to an increased inhibition of the thalamocortical projections, and thus to impoverished movements.

This fact was supported by the results of lesioning the STN in the MPTP model of PD in monkeys, leading to clinical improvement and decreased extracelular action potential discharge at the STN [13]. The increased activity at these nuclei is a neurophysiologic hallmark of PD, and this finding has influenced the surgical treatment of $\mathrm{PD}$, since this hyperactivity is in contrast with that of the adjacent structures, permitting its identification during the intraoperative recording [14].

\section{SURGICAL TREATMENT OF PD}

Besides a better comprehension of the functional or- 
ganization of BG, technological advances in surgical procedures, neuroimaging and neurophysiological recordings have contributed to the increased interest in functional Neurosurgery for PD.

Generally speaking, the ideal candidate for this procedure is a PD patient, preferably under 70 years old, diagnosed more than 5 years earlier, and with the presence of motor complications resistant to pharmacological treatment, but having had any significant improvement with dopaminergic drugs, and not presenting any cognitive impairment, uncontrolled psychiatric disorder or any other comorbidity preventing him or her from a surgical procedure [15]. The surgical targets for PD are the GPi and the STN, being this last the preferred one in most of the cases $[16,17]$.

In order to identify the target, imaging techniques are used (merging of CT and MR), permitting a direct visualization of the structures, or an indirect calculation measuring the distances from known references and comparing them with an atlas. Later, during surgery, the recording of the neuronal action potentials through a microelectrode, implanted with the aid of a stereotactic system, confirms the location of the target nucleus, defines the somatomotor area, and delimitates the frontiers with other structures [18-21].

Once the target is identified, the surgical procedure can consist either of a thermolesion (pallidotomy, subthalamotomy), or the implantation of a macroelectrode within the nucleus that later will be connected to a pulse generator, permitting the deep brain stimulation (DBS) in a chronic way.

DBS, of which we are commemorating the first 25 since the first implant, permits the programming of the stimulator in such a way that undesirable side effects through the stimulation of structures near the target are avoided. Also, it provokes less side effects over cognitive and language aspects that the definitive lesion.

\section{RHYTHM SYNCHRONIZATION OF THE BASAL GANGLIA IN PD}

Thus, functional neurosurgery brings us the opportunity to study the physiology of BG in the parkinsonian human though the recording of the neuronal activity in vivo, constituting the most direct approximation to the study of the functional state of the nervous system. And this can be made in two ways: the recording of the unitary neuronal activity during the microelectrode insertion at surgery, and the recording of the local field potentials (LFP) through the implanted macroelectrode before its definitive connection to the pulse generator.

LFP possibly represent the sum of the simultaneous afferent dendritic currents of a huge number of neurons, being thus not only a measure of the activity of a neuronal group, but also of a functional state of synchrony in the postsynaptic activity of this group of neurons [22].

The analysis of the LFP in implanted patients has shown the presence of an important oscillatory activity [24-32]. The analysis of this oscillatory activity has risen a great interest in the scientific community, and even if its functional role is still to be determined, the most attractive aspect of this activity is its implication in information coding processes that promote synchrony between neurons from the same or distant areas involved in a concrete motor, perceptive or cognitive activity [33].

The study of LPF is much more profitable than that of the intraoperative activity, since it permits to explore the patient in a much more comfortable and permissive situation than inside the operating room, being it possible to study the patient while applying motor and cognitive paradigms or pharmacologic tests.

The analysis of LFP is similar to that of other signals reflecting the activity of a neuronal group, such as the electroencephalographic activity (EEG). Its most basic tool is the fast Fourier transform (FFT), which provides the power spectrum of the analyzed signal, and is a static measure, i.e., it measures the contribution of each fundamental frequency to the signal, without having into account the time factor. If the dynamic behavior, such as the changes in the oscillations at several frequencies along time, is to be measured, then the time-frequency transforms may be used. These provide a representation showing the evolution of the energy corresponding to each frequency along the time. Also, the response of the neuronal activity to a concrete stimulus or event can be recorded, determining the amplitude of the signal at a particular frequency in each sweep, and promediating the signal to obtain desynchronization (ERD) or synchronization (ERS) response patterns [34,35].

The oscillatory activity recorded in implanted patients can be characterized in different frequency bands, conventionally called theta, alpha, beta and gamma, in relationship to the frequency ranges known in EEG, although they do not correspond exactly to each other.

Since the first evidence of these bands was published in 2001 [23] a fact which was confirmed by later studies [24-32,36] was that this oscillatory activity was modulated by the dopaminergic activation state, in such a way that in the absence of medication (OFF medication) the beta band $(10-30 \mathrm{~Hz})$ was predominating in the frequency spectrum, but this situation changed after the intake of levodopa (ON medication), when the beta band attenuated or even disappeared, while a peak in the gamma frequency range $(60-70 \mathrm{~Hz})$ appeared, dominating the spectrum in $\mathrm{ON}$ state, even if inconstantly (Figure 1).

Besides the dopaminergic stimulation state, other studies have also demonstrated the relationship between the oscillatory activity and other clinical PD manifestations, such as rest tremor, where a dominant peak at the 


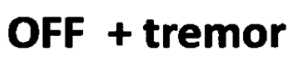

(4-6Hz)
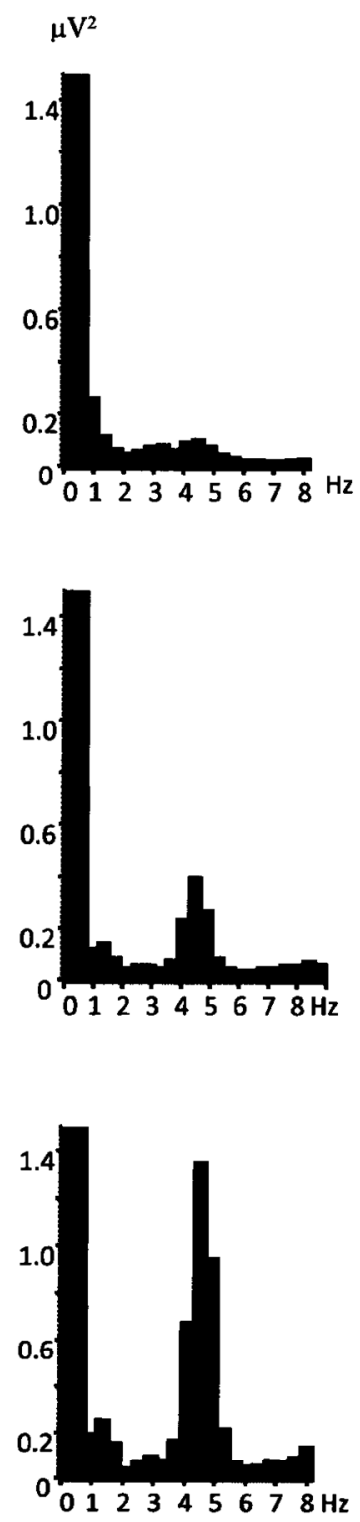

(a)

\section{OFF \\ (11-30Hz)}
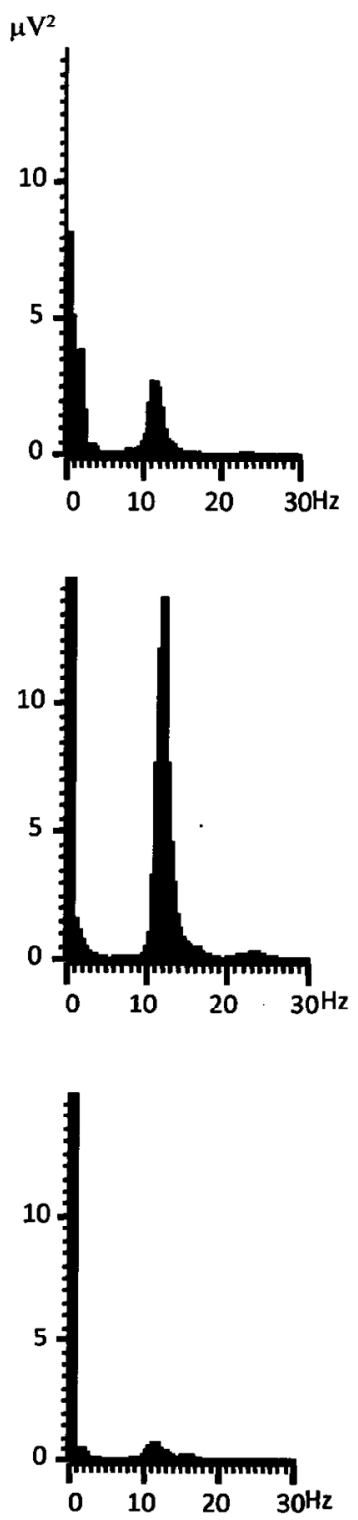

(b)

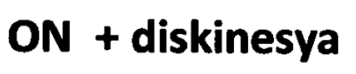

(7-9Hz)
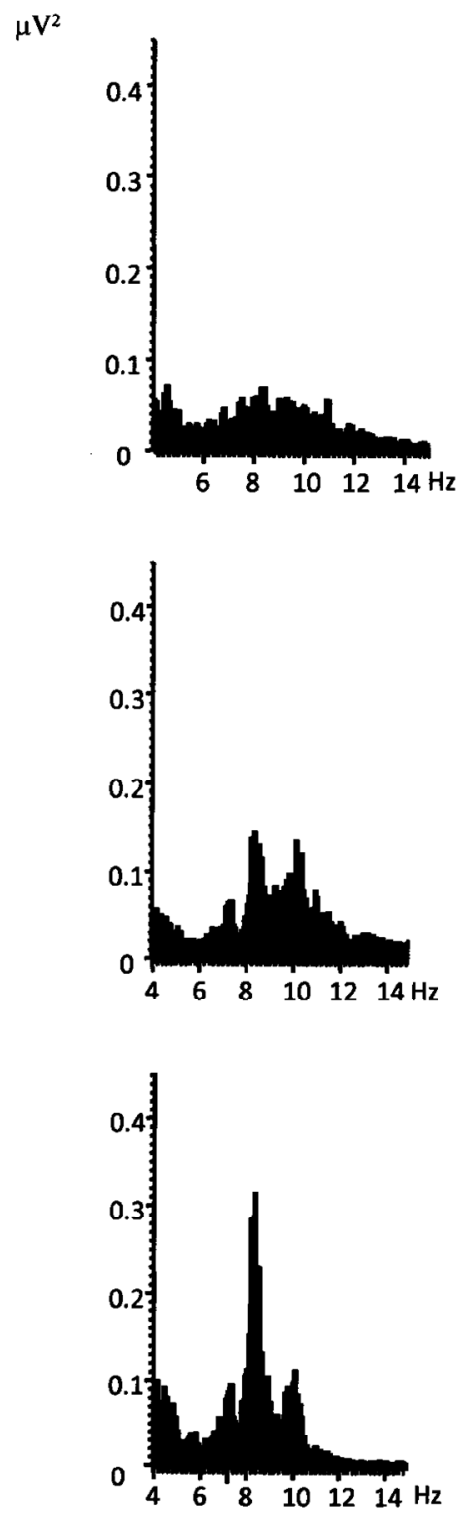

(c)
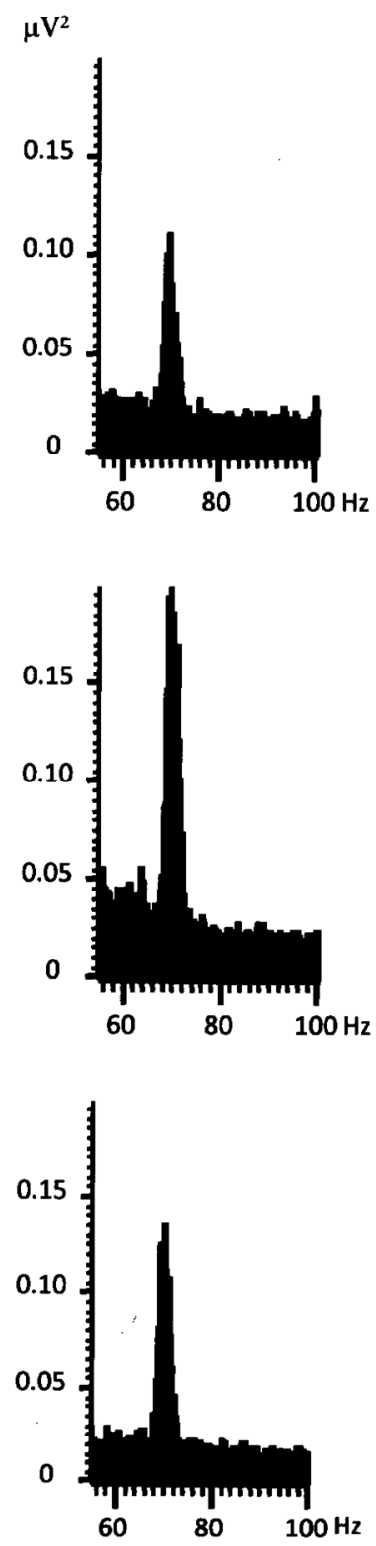

(d)

Figure 1. STN Local Field Potentials power spectra from different phases of a pharmacological cycle from off to on medication, showing the predominate frequency peaks in hertz. (a) OFF medication with rest tremor; (b) OFF medication without tremor, with the characteristic beta activity $(11-30 \mathrm{~Hz})$; (c) ON medication with peak-dose dyskinesia; (d) ON medication with the characteristic gamma $(>60 \mathrm{~Hz})$ activity.

tremor frequency is found [26,38,65].

Also in those patients developing diskynesias during the ON phase $[32,39,40]$ a tight relationship between these and the presence of a frequency band in a lower range $(4-8 \mathrm{~Hz})$ has been found. This spatio-temporal relationship is very precise, since this has been found only at the STN contralateral to the diskynetic extremities and it took place only during the ON state in the case of peak-dose diskynesias, or in the middle of the ONOFF cycle in the case of biphasic diskynesias [32,40].

The activity in the beta range has been shown as the most consistent finding in the cortico-BG network in the 
PD state, and it has been at large the most studied one.

A controversy was set up since the beginning about the meaning of this beta band, which still lingers, in relationship to whether it is only an epiphenomenon of the pharmacological status of dopaminergic impregnation, or if it really has a functional significance [41,42].

The first approximation would be to ask if the oscillatory activity in the beta range is a characteristic exclusive to the PD status, or rather it is an increase or a degeneration of the physiologic mechanisms.

Evidently, the physiopathologic interpretation of recording in PD patients is limited by the lack of a control group, since those recordings cannot be made in healthy subjects. But studies in rats and primates, and also in patients with STN recordings due to other indications [43-46], have shown the presence of this beta activity, suggesting that this activity may have a physiologic significance in normal conditions. It has been even suggested that this activity could represent a functional role in the regulation of movement, favoring the processes related to the maintenance of the postural tone, or to the coding spatio-temporal information between the groups of neurons involved in a sequence of movement [47].

In studies performed in implanted PD patients, it has been possible to relate in a more precise way this excess of synchronization of the beta band with the PD clinical features. Thus, Kuhn et al. [48], analyzed the LFP of 30 patients and their clinical features, observing that the degree of improvement in rigidity and bradikynesia, measured with the UPDRs-III scale, was correlated with the degree of suppression of the beta band in the $10-30$ $\mathrm{Hz}$ range. It is interesting to note that the improvement due to DBS is inversely correlated with the beta range oscillatory activity, suggesting that DBS can suppress this pathologic activity [49-52]. Thus, Eusebio et al. [53], have registered LFP in 16 patients while they were subjected to DBS at $130 \mathrm{~Hz}$. This stimulation progressively suppressed the peak activity of LFP in the frequency range of $11-30 \mathrm{~Hz}$ as the intensity of the stimulation was increased, and the suppression appeared at clinically effective intensity values.

Another way to understand the antikynetic significance of the beta band is to analyze its behavior in relationship with an ongoing voluntary movement. Different authors [27,30,36,54-57] agree with the existence of a loss of energy in the beta band before and during a voluntary movement, followed by its increase after the movement has stopped. Furthermore, experiments based on "go-no go" movement paradigms [52], which try to cancel a preplanned movement, show that after the alerting cue, there is a desynchronization, or loss of activity in the beta band, that decreases even more when the instruction to move (go) is confirmed. However, when the alerting cue is followed by the order to cancel the programmed move- ment (no go), the beta desynchronization stops prematurely. It may be thus concluded that the beta synchronization at the STN seems an important determinant as to whether enable or suppress the motor planning [30].

Up to now, all the previously shown evidences could be considered as mere correlations of the degree of beta synchronization with a clinical state or a phase of the movement process [42]. More direct evidence would require demonstrating a significant disabling of the motor activity produced by direct stimulation of the STN precisely at the beta frequency range. This has been demonstrated recently [58] in a series of 22 patients without medication who received randomly ether $20 \mathrm{~Hz}$, $50 \mathrm{~Hz}$ or $130 \mathrm{~Hz}$ stimulation, while they were tested for the manual performance of a simple motor task, such as the tapping test. Stimulation at the beta range $(20 \mathrm{~Hz})$ worsened the motor task performance in a significant way $(8 \%)$, while it was not affected by stimulation in other frequency ranges $(50$ or $130 \mathrm{~Hz})$. This study provides the first evidence that the excessive beta synchronization could be a cause of the motor slowing, rather than an epiphenomenon. Nevertheless, we have frequently observed in the clinical practice that lowering the frequency of stimulation in implanted patients without the corresponding increase in intensity to maintain the total charge which is administered has an effect similar to stopping the stimulation, thus the intrinsic effect of frequency would be controversial (personal observation).

\section{THEORICAL AND PRACTICAL APPLICATIONS OF THE OSCILLATORY MODEL}

The model of functional organization we have reviewed constitutes an obligatory reference to understand the functional organization of basal ganglia. Although it has been expanded with the inclusion of other structures and pathways [59], in its original conception it considers the coding of information as an increment or decrement of neuronal firing, a point which implies a series of paradoxes difficult to conciliate with surgical results, such as that thalamic lesioning should worsen the motor state of a PD patient or that pallidotomy should worsen diskynesias, since suppressing NST or output nuclei activity should disinhibit the thalamus.

The analysis of the patterns of neuronal activity based on oscillations could provide us a more dynamic vision about the organization of the system and its pathology: excessive beta synchronization would represent an abnormal noise signal driving the system busy and nonoperative, blocking the normal information outflow through the BG and avoiding the proper selection of the appropriate motor program. Thus, surgery of BG with DBS would functionally counteract these oscillations, restoring the system and permitting an improvement of 
akynesia and the suppression of abnormal movements, conciliating the classical paradox $[60,61]$.

But besides these theorical considerations there are other more practical ones. Contrasting the antikynetic character of the beta band we have reviewed earlier, an increase, of the gamma band $(60-80 \mathrm{~Hz})$ is associated with an improvement of the motor state of the patients in ON state, with an inverse relationship with the beta band through the on-off pharmacological cycle (32), using the motor subscale of UPDRS [62], and a synchrony with the execution of movement $[25,56,57]$.

In new attempts to test more directly the relationship between gamma band and motor performance, recently Tsang et al. [63] examined the effect of DBS at individual frequencies. They determined the dominant frequency peaks in on and off states, and during voluntary movement. Then they stimulated at different frequencies (theta-beta-delta) and demonstrated that stimulation at gamma frequency at the intrinsic range (not the conventionally applied $130 \mathrm{~Hz}$ ) diminishes the PD symptoms the same way as conventional DBS. Thus, in the future, a greater selectivity in DBS patterns will be used, able not only to neutralize the abnormal frequency pattern, but also to actively promote the motor ability in PD. Also recently [64] it has been precisely corroborated a fact that can be seen frequently during microelectrode recording: a rich STN recording of beta frequency isolated neuronal activity warrants a higher probability of achieving a good response when the macroelectrode is inserted at that location. These authors analyzed the recordings in 128 implanted patients, being it possible to distinguish the dorsal versus ventral border of the STN, since the dorsal region (DLOR) shows the presence of beta range oscillatory activity. They also observed an important correlation (0.67) between the percentage improvement in UPDRS with chronic DBS and the length of recorded DLOR, but not with the total length of the recorded STN $(p=0.11)$ concluding that the length of recorded DLOR of the STN at the implanted trajectory is correlated with the response of motor symptoms to DBS.

In conclusion, functional neurosurgery of BG for PD treatment, besides being an efficacious and safe therapeutic option for PD treatment with pharmacologically uncontrolled symptoms, brings us the unique opportunity to deepen in the knowledge of PD's physiopathology, and possibly in the future it will let us select the appropriate target and the optimal chronic stimulation pattern.

\section{REFERENCES}

[1] Marttila, R.J. and Rinne, U.K. (1976) Epidemiology of Parkinson's disease in Finland. Acta Neurologica Scandinavica, 53, 81-102. doi:10.1111/j.1600-0404.1976.tb04328.x
[2] Kuopio, A.M., Marttila, R.J., Helenius, H. and Rinne, U.K. (1999) Changing epidemiology of Parkinson's disease in southwestern Finland. Neurology, 52, 302-308. doi:10.1212/WNL.52.2.302

[3] Forno, L.S. (1992) Neuropathologic features of Parkinson's, Huntington's, and Alzheimer's diseases. Annals of the New York Academy of Sciences, 648, 6-16. doi:10.1111/j.1749-6632.1992.tb24519.x

[4] Silva, M.T. and Saphira, A.H.V. (2001) Parkinson's disease En Mattson MP. Edit Pathogenensis of neurodegenerative disorders. Humana Press, Totowa, 53-79.

[5] Fahn, S., Libsch, L.R. and Cutler, R.W. (1971) Monoamines in the human neostriatum: Topographic distribution in normals and in Parkinson's disease and their role in akinesia, rigidity, chorea, and tremor. Journal of the Neurological Sciences, 14, 427-455 doi:10.1016/0022-510X(71)90178-X

[6] Cotzias, G.C., Van Woert, M.H. and Schiffer, L.M. (1967) Aromatic amino acids and modification of Parkinsonism. The New England Journal of Medicine, 276, 374-379. doi:10.1056/NEJM196702162760703

[7] Yahr, M.D., Duvoisin, R.C., Schear, M.J., Barrett, R.E. and Hoehn, M.M. (1969) Treatment of Parkinsonism with levodopa. Archives of Neurology, 21, 343-354. doi:10.1001/archneur.1969.00480160015001

[8] Schrag, A., Ben-Shlomo, Y., Brown, R., Marsden, C.D. and Quinn, N. (1998) Young-onset Parkinson's disease revisited clinical features, natural history, and mortality. Movement Disorders, 13, 885-894. doi: $10.1002 / \mathrm{mds} .870130605$

[9] Obeso, J.A., Grandas, F., Vaamonde, J., Luquin, M.R., Artieda, J., Lera, G., Rodríguez, M.C. and Martinez-Lage, J.M. (1989) Motor complications associated with chronic levodopa therapy in Parkinson's disease. Neurology, 39, 11-19.

[10] Obeso, J.A., Rodríguez-Oroz, M.C., Chana, P., Lera, G., Rodríguez, M. And Olanow, C.W. (2000) The evolution and origin of motor complications in Parkinson's disease. Neurology, 55, S13-S20.

[11] Obeso, J.A., Olanow, C.W. and Nutt, J.G. (2000) Levodopa motor complications in Parkinson's disease. Trends in Neurosciences, 23, S2-S7. doi:10.1016/S1471-1931(00)00031-8

[12] Albin, R.L., Young, A.B. and Penney, J.B. (1989) The functional anatomy of basal ganglia disorders. Trends in Neurosciences, 12, 366-375. doi:10.1016/0166-2236(89)90074-X

[13] DeLong, M.R. (1990) Primate models of movement disorders of basal ganglia origin. Trends in Neurosciences, 13, 281-285. doi:10.1016/0166-2236(90)90110-V

[14] Obeso, J.A., Rodríguez, M.C. and DeLong, M.R. (1997) Surgery for Parkinson's disease. Journal of Neurology, Neurosurgery \& Psychiatry, 62, 2-8. doi:10.1136/jnnp.62.1.2

[15] Rodriguez, R.L., Fernandez, H.H., Haq, I. and Okun, M.S. (2007) Pearls in patient selection for deep brain stimulation. Neurologist, 13, 253-260. doi:10.1097/NRL.0b013e318095a4d5 
[16] Bronstein, J.M., Tagliati, M., Alterman, R.L., Lozano, A.M., Volkmann, J., Stefani, A., Horak, F.B., Okun, M.S., Foote, K.D., Krack, P., Pahwa, R., Henderson, J.M., Hariz, M.I., Bakay, R.A., Rezai, A., Marks Jr., W.J., Moro, E., Vitek, J.L., Weaver, F.M., Gross, R.E. and DeLong, M.R. (2011) Deep brain stimulation for Parkinson disease: An expert consensus and review of key issues. Archives of Neurology, 68, 165. doi:10.1001/archneurol.2010.260

[17] Moro, E., Scerrati, M., Romito, L.M., Roselli, R., Tonali, P., Albanese, A. (1999) Chronic subthalamic nucleus stimulation reduces medication requirements in Parkinson's disease. Neurology, 53, 85-90. doi:10.1212/WNL.53.1.85

[18] Magariños-Ascone, C.M., Figueiras-Mendez, R., RivaMeana, C. and Cordoba-Fernández, A. (2000) Subthalamic neuron activity related to tremor and movement in Parkinson's disease. European Journal of Neuroscience, 12, 2597-2607. doi:10.1046/j.1460-9568.2000.00127.x

[19] Magnin, M., Morel, A. and Jeanmonod, D. (2000) Single-unit analysis of the pallidum, thalamus and subthalamic nucleus in parkinsonian patients. Neuroscience, 96, 549-564. doi:10.1016/S0306-4522(99)00583-7

[20] Hutchison, W.D., Allan, R.J., Opitz, H., Levy, R., Dostrovsky, J.O., Lang, A.E. and Lozano, A.M. (1998) Neurophysiological identification of the subthalamic nucleus in surgery for Parkinson's disease. Archives of Neurology, 44, 622-628.

[21] Rodríguez-Oroz, M.C., Rodríguez, M., Guridi, J., Mewes, K., Chockkman, V., Vitek, J., DeLong, M.R. and Obeso, J.A. (2001) The subthalamic nucleus in Parkinson's disease: Somatotopic organization and physiological characteristics. Brain, 124, 1777-1790. doi:10.1093/brain/124.9.1777

[22] Schnitzler, A. and Gross, J. (2005) Normal and pathological oscillatory communication in the brain. Nature Reviews Neuroscience, 6, 285-296. doi:10.1038/nrn1650

[23] Brown, P., Oliviero, A., Mazzone, P., Insola, A., Tonali, P. and Di Lazzaro, V. (2001) Dopamine dependency of oscillations between subthalamic nucleus and pallidum in Parkinson's disease. The Journal of Neuroscience, 21, 1033.

[24] Brown, P. and Williams, D. (2005) Basal ganglia local field potential activity: Character and functional significance in the human. Clinical Neurophysiology, 116, 2510-2519. doi:10.1016/j.clinph.2005.05.009

[25] Priori, A., Foffani, G., Pesenti, A., Bianchi, A., Chiesa, V., Baselli, G., Caputo, E., Tamma, F., Rampini, P., Egidi, M., Locatelli, M., Barbieri, S. and Scarlato, G. (2002) Movement-related modulation of neural activity in human basal ganglia and its L-DOPA dependency: Recordings from deep brain stimulation electrodes in patients with Parkinson's disease. Neurological Sciences, 23, S101-S102. doi:10.1007/s100720200089

[26] Priori, A., Foffani, G., Pesenti, A., Tamma, F., Bianchi, A.M., Pellegrini, M., Locatelli, M., Moxon, K.A. and Villani, R.M. (2004) Rhythm-specific pharmacological modulation of subthalamic activity in Parkinson's disease.
Experimental Neurology, 189, 369.

doi:10.1016/j.expneurol.2004.06.001

[27] Williams, D., Kühn, A., Kupsch, A., Tijssen, M., van Bruggen, G., Speelman, H., Hotton, G., Yarrow, K. and Brown, P. (2003) Behavioural cues are associated with modulations of synchronous oscillations in the human subthalamic nucleus. Brain, 126, 1975. doi:10.1093/brain/awg194

[28] Williams, D., Tijssen, M., Van Bruggen, G., Bosch, A., Insola, A., Di Lazzaro, V., Mazzone, P., Oliviero, A., Quartarone, A., Speelman, H. and Brown. P. (2002) Dopamine-dependent changes in the functional connectivity between basal ganglia and cerebral cortex in humans. Brain, 125, 1558-1569. doi:10.1093/brain/awg267

[29] Silberstein, P., Kühn, A.A., Kupsch, A., Trottenberg, T., Krauss, J., Wöhrle, J.C., Mazzone, P., Insola, A., Di Lazzaro, V., Oliviero, A., Aziz, T. and Brown, P. (2003) Patterning of globus pallidus local field potentials differs between Parkinson's disease and dystonia. Brain, 126, 2597. doi:10.1093/brain/awh106

[30] Kühn, A.A., Williams, D., Kupsch, A., Limousin, P., Hariz, M., Schneider, G.-H., Yarrow, K. and Brown, P. (2004) Event-related beta synchronization in human subthalamic nucleus correlates with motor performance. Brain, 127, 735.

[31] Fogelson, N., Kuhn, A.A., Silberstein, P., Limousin, P.D., Hariz, M., Trottenberg, T., Kupsch, A. and Brown, P. (2005) Frequency dependent effects of subthalamic nucleus stimulation in Parkinson's disease. Neuroscience Letters, 382, 5-9. doi:10.1016/j.neulet.2005.02.050

[32] Alonso-Frech, F., Zamarbide, I., Alegre, M., RodríguezOroz, M.C., Guridi, J., Manrique, M., Valencia, M., Artieda, J. and Obeso, J.A. (2006) Slow oscillatory activity and levodopa-induced dyskinesias in Parkinson's disease. Brain, 129, 1748-1757. doi:10.1093/brain/awl103

[33] Varela, F., Lachaux, J.P., Rodríguez, E. And Martinerie, J. (2001) The brainweb: Phase synchronization and largescale integration. Nature Reviews Neuroscience, 2, 229239. doi: $10.1038 / 35067550$

[34] Challis, R.E. and Kitney, R.I. (1990) Biomedical signal processing (in four parts). Part 1. Time-domain methods. Medical \& Biological Engineering \& Computing, 28, 509-524. doi:10.1007/BF02442601

[35] Challis, R.E. and Kitney, R.I. (1991) Biomedical signal processing (in four parts). Part 3. The power spectrum and coherence function. Medical \& Biological Engineering \& Computing, 29, 225-241. doi:10.1007/BF02446704

[36] Levy, R., Ashby, P., Hutchinson, W.D., Lang, A.E., Lozano, A.M. and Dostrovsky, J.O. (2002) Dependence of subthalamic nucleus oscillations on movement and dopamine in Parkinson's disease. Brain, 125, 1196-1209. doi:10.1093/brain/awf128

[37] Bergman, H., Feingold, A., Nini, A., Raz, A., Slovin, H., Abeles, M. and Vaadia, E. (1998) Physiological aspects of information processing in the basal ganglia of normal and Parkinsonian primates. Trends in Neurosciences, 21, 32 38. doi:10.1016/S0166-2236(97)01151-X 
[38] Levy, R., Hutchison, W.D., Lozano, A.M. and Dostrovsky, J.O. (2002) Synchronized neuronal discharge in the basal ganglia of Parkinsonian patients is limited to oscillatory activity. The Journal of Neuroscience, 22, 2855-2861.

[39] Foffani, G., Ardolino, G., Meda, B., Egidi, M., Rampini, P., Caputo, E., Baselli, G. and Priori, A. (2005) Altered subthalamo-pallidal synchronisation in parkinsonian dyskinesias. Journal of Neurology, Neurosurgery and Psychiatry, 76, 426-428. doi:10.1136/jnnp.2004.043547

[40] Alegre, M., López-Azcárate, J., Alonso-Frech, F., Rodríguez-Oroz, M.C., Valencia, M., Guridi, J., Artieda, J. and Obeso, J.A. (2012) Subthalamic activity during diphasic dyskinesias in Parkinson's disease. Movement Disorders, 27, 1178-1181. doi:10.1002/mds. 25090

[41] Brown, P. (2003) Oscillatory nature of human basal ganglia activity: Relationship to the pathophysiology of Parkinson's disease. Movement Disorders, 18, 357-363. doi: $10.1002 / \mathrm{mds} .10358$

[42] Eusebio, A. and Brown, P. (2007) Oscillatory activity in the basal ganglia. Parkinsonism \& Related Disorders, 13, S434-S436. doi:10.1016/S1353-8020(08)70044-0

[43] Vorobyov, V.V., Schibaev, N.V., Morelli, M. and Carta, A.R. (2003) EEG modifications in the cortex and striatum after dopaminergic priming in the 6-hydroxydopamine rat model of Parkinson's disease. Brain Research, 972, 177185. doi:10.1016/S0006-8993(03)02528-9

[44] Berke, J.D., Okatan, M., Skurski, J. and Eichenbaum, H.B. (2004) Oscillatory entrainment of striatal neurons in freely moving rats. Neuron, 43, 883-896. doi:10.1016/j.neuron.2004.08.035

[45] Courtemanche, R., Fujii, N. and Graybiel, A.M. (2003) Synchronous, focally modulated beta-band oscillations characterize local field potential activity in the striatum of awake behaving monkeys. The Journal of Neuroscience, 23, 11741-11752.

[46] Sochurkova, D. and Rektor, I. (2003) Event-related desynchronization/synchronization in the putamen. An SEEG case study. Experimental Brain Research, 149, 401-404.

[47] Steigerwald, F., Pötter, M., Herzog, J., Pinsker, M., Kopper, F., Mehdorn, H., Deuschl, G. and Volkmann, J. (2008) Neuronal activity of the human subthalamic nucleus in the parkinsonian and nonparkinsonian state. Journal of Neurophysiology, 100, 2515-2524. doi:10.1152/jn.90574.2008

[48] Kühn, A.A., Tsui, A., Aziz, T., Ray, N., Brücke, C., Kupsch, A., Schneider, G.H. and Brown, P. (2009) Pathological synchronisation in the subthalamic nucleus of patients with Parkinson's disease relates to both bradykinesia and rigidity. Experimental Neurology, 215, 380387. doi:10.1016/j.expneurol.2008.11.008

[49] Wingeier, B, Tcheng, T, Koop, M.M., Hill, B.C., Heit, G. and Bronte-Stewart, H.M. (2006) Intra-operative STN DBS attenuates the prominent beta rhythm in the STN in Parkinson's disease. Experimental Neurology, 197, 244251. doi:10.1016/j.expneurol.2005.09.016

[50] Bronte-Stewart, H., Barberini, C., Koop, M.M., et al. (2009) The STN beta-band profile in Parkinson's disease is stationary and shows prolonged attenuation after deep brain stimulation. Experimental Neurology, 215, 20-28.

[51] Brown, P., Mazzone, P., Oliviero, A., et al. (2004) Effects of stimulation of the subthalamic area on oscillatory pallidal activity in Parkinson's disease. Experimental Neurology, 188, 480-490.

[52] Kuhn, A.A., Kempf, F., Brucke, C., et al. (2008) Highfrequency stimulation of the subthalamic nucleus suppresses oscillatory beta activity in patients with Parkinson's disease in parallel with improvement in motor performance. The Journal of Neuroscience, 28, 61656173.

[53] Eusebio, A., Thevathasan, W., Doyle, G. L., Pogosyan, A., Bye, E., Foltynie, T., Zrinzo, L., Ashkan, K., Aziz, T. and Brown, P. (2011) Deep brain stimulation can suppress pathological synchronisation in parkinsonian patients. Journal of Neurology, Neurosurgery and Psychiatry, 82, 569-573. doi:10.1136/jnnp.2010.217489

[54] Cassidy, M., Mazzone, P., Oliviero, A., Insola, A., Tonali, P., Di Lazzaro, V. and Brown, P. (2002) Movement related changes in synchronization in the human basal ganglia. Brain, 125, 1235-1246. doi:10.1093/brain/awf135

[55] Doyle, L.M., Kuhn, A.A., Hariz, M., Kupsch, A., Schneider, G.H. and Brown, P. (2005) Levodopa-induced modulation of subthalamic beta oscillations during selfpaced movements in patients with Parkinson's disease. European Journal of Neuroscience, 21, 1403-1412. doi:10.1111/j.1460-9568.2005.03969.x

[56] Alegre, M., Alonso-Frech, F., Rodriguez-Oroz, M.C., Guridi, J., Zamarbide, I., Valencia, M., Manrique, M., Obeso, J.A. and Artieda, J. (2005) Movement-related changes in oscillatory activity in the human subthalamic nucleus: Ipsilateral vs. contralateral movements. European Journal of Neuroscience, 22, 2315-2324. doi:10.1111/j.1460-9568.2005.04409.x

[57] Paradiso, G., Saint-Cyr, J.A., Lozano, A.M., Lang, A.E. and Chen, R. (2003) Involvement of the human subthalamic nucleus in movement preparation. Neurology, 61, 1538-1545. doi:10.1212/01.WNL.0000096021.28967.57

[58] Chen, C.C., Litvak, V., Gilbertson, T., Kühn, A., Lu, C.S., Lee, S.T., Tsai, C.H., Tisch, S., Limousin, P., Hariz, M. and Brown, P. (2007) Excessive synchronization of basal ganglia neurons at $20 \mathrm{~Hz}$ slows movement in Parkinson's disease. Experimental Neurology, 205, 214-221. doi:10.1016/j.expneurol.2007.01.027

[59] Obeso, J.A., Rodríguez-Oroz, M.C., Rodríguez, M., Lanciego, J.L., Artieda, J., Gonzalo, N. and Olanow, C.W. (2000) Pathophysiology of the basal ganglia in Parkinson's disease. Trends in Neurosciences, 23, S8-S19. doi:10.1016/S1471-1931(00)00028-8

[60] Brown, P. and Eusebio, A. (2008) Paradoxes of functional neurosurgery: Clues from basal ganglia recordings. $\mathrm{Mo}-$ vement Disorders, 23, 12-20. doi:10.1002/mds.21796

[61] Marsden, C.D. and Obeso, J.A. (1994) The functions of the basal ganglia and the paradox of stereotaxic surgery in Parkinson's disease. Brain, 117, 877-897. doi:10.1093/brain/117.4.877

[62] Kühn, A.A., Kupsch, A., Schneider, G.H. and Brown, P. 
(2006) Reduction in subthalamic $8-35 \mathrm{~Hz}$ oscillatory activity correlates with clinical improvement in Parkinson's disease. European Journal of Neuroscience, 23, 19561960.

[63] Tsang, E.W., Hamani, C., Moro, E., Mazzella, F., Saha, U., Lozano, A.M., Hodaie, M., Chuang, R., Steeves, T., Lim, S.Y., Neagu, B. and Chen, R. (2012) Subthalamic deep brain stimulation at individualized frequencies for Parkinson disease. Neurology, 78, 1930-1938. doi:10.1212/WNL.0b013e318259e183

[64] Zaidel, A., Spivak, A., Grieb, B., Bergman, H. and Israel,
Z. (2010) Subthalamic span of beta oscillations predicts deep brain stimulation efficacy for patients with Parkinson's disease. Brain, 133, 2007-2021. doi:10.1093/brain/awq144

[65] Reck, C., Florin, E., Wojtecki, L., Krause, H., Groiss, S., Voges, J., Maarouf, M., Sturm, V., Schnitzler, A. and Timmermann, L. (2009) Characterisation of tremor-associated local field potentials in the subthalamic nucleus in Parkinson's disease. European Journal of Neuroscience, 29, 599-612. 